\title{
Sympathy for the Traitor
}

Polizzotti, Mark. 2018. Sympathy for the Traitor. Cambridge \& Massachusetts: The MIT Press.

Reviewed by RANDHEER KOUR

Translation Studies, as a discipline, deals with translation from diverse perspectives. Being a new field of study in the era of cross-culturalism, Translation Studies extends the debate of 'us versus them' to 'original versus translation.' In the process, it is expected to encounter the gaps between theory and practice and reflect upon them. The recent scholarships in the field mostly train their focus on contesting translation theories. This lopsided growth in the discipline has marginalized the translators and translations. The book Sympathy for The Traitor by Mark Polizzotti drifts away from adding more theoretical scholarship in the shipping cart of translation. Rather, it moves closer to the translator and the act of translation. Sympathy for the Traitor brings the translator and the act of translation at the centre stage of translation discourse. The word traitor in the title is taken from the Italian word "traduttore, traditore" which means a traitor and refers to the translator. This reflects how the translator has been denigrated as a traitor but the author designates him as a "creative artist who is at par with the author being translated" (p. xiv). This book does not speak about translation rather performs the different matrices of translation. It does not discuss the theories of translation but the varied practices in translation. The author envisions to sketch "the art and craft of translation" (xii). Published by MIT press in 2018, this is Mark Polizzotti's seventh book as an independent author. The author mentions that some chapters of this book were earlier published in journals like Parnassus, New Ohio Review, and Translation Review. It is divided into nine chapters and there is an introduction. These nine chapters are expanded in 151 
pages excluding the paratext. The notes on each chapter are given at the end, which complements the subject under study but breaks the flow of communication. The introduction talks about some ground rules and provides instructions for the reader. The important one is that this book does not present any new theory; rather, it is an anti-theory approach towards the discipline of Translation Studies.

The first chapter explores the fundamental question of the very existence of the translation and gauges the different possibilities of translation. It discusses how the authortranslator relationship changes over time and how the fundamental question is linked to the cultural context of the source and target text.

The second chapter traces three roles of the translator through different ages. It elaborates on how they performed the roles of Saints of Septuagint in carrying the message in ancient times. In the medieval age, they were charged with heresy, killed, and became martyrs. This chapter focuses on different biblical translations and the brunt of heresy faced by many translators such as John Wycliff, William Tyndale, and others. However, in modern times, the translators are treated as spies, "...translation and spying are natural bedfellows: both involve double allegiances, parallel modes of expression..." (33).

The third chapter opens with the debate of im/pure language, started by Friedrich Schleiermacher and Walter Benjamin about which the author is very critical. He strikes hard at the translation theorists, who, according to him, do not contribute to translating better.

The fourth chapter throws light on the age-old debate between faithful and felicity. Looking back at what the doyens of Translation Studies have already said, the author directs for representation rather than reproduction in which 'respect' and 
'empathy' for the source text should be the core concerns for the translator.

Chapter five is about what is 'missed' in the translation, especially the voids, the gaps that occur due to miss/less understanding of the cultural contexts of the source text. The author claims and elucidates that these silences and gaps can be bridged.

The title of the book Sympathy for the Traitor is the sixth chapter. In this chapter, the author demonstrates with excerpts from French novels, the challenges he faced in translating into English. He mended many things to match the original voice and hence can be labelled as a traitor. This chapter also confronts the question of evaluation such as how to judge a good translation and later defines the parameters for the same. According to him, "a good translation, aims to enhance and refresh, not to denature, not to obscure, not to petrify"(110).

The seventh chapter discusses the different possibilities of the translation of the poetry which is otherwise considered not well-suited for translation. The focus of this chapter is the Nabokov translation of Pushkin poetry and detailed descriptions about what is lost in the English translation.

The eighth chapter brings to centre those areas of translation that are found in the periphery because of their strange nature which makes them untranslatable. In this chapter, the author concentrates on the Georges Perec's lipogrammatic novel La Disparition and the challenges of sound-based translation.

In the last chapter, the author throws light on the great mistranslations in translation history like Adam's apple, Moses's head, and Satanic verses, and addresses a fundamental question; does translation matter? In the later part, he convinces us by giving references from the geopolitics of the modern nation-states that, lot much had been saved if the 
proper translation had been done. This part of the chapter also discusses the importance of cultural amplitude in translation. He makes his position strong after establishing his argument that the translation does matter.

The acts of translation that are demonstrated and discussed become the most important feature of this book. Most of the examples represent French to English translation. The discussions majorly concern the domain of literary translations. The concise length, lucid language, and coherence of ideas keep the reader's journey quite delightful. The readers may feel as they were attending a live session or a workshop on translation. The discussions are exceedingly relevant for professional translators. They offer insight into various translation-related issues that the theoretical textbooks on Translation Studies do not address adequately. The only perceivable disadvantage for a reader is that if $\mathrm{s} /$ he does not know French, the source word or phrase of the illustration may be difficult to follow. This book is a series of questions that are considered highly relevant to the discipline of Translation Studies. The book keeps exploring the possibilities of translation and concludes with the perspective that 'translation' matters and makes a difference. This book convincingly meets the expectations it creates in the introduction. As claimed, it is a successful attempt to remove the misconceptions that surround the discipline of Translation Studies. The author's vast experience of translating over forty books reflects in the language, content, and style of the chapters that keep the readers engaged even if one does not have any theoretical knowledge in the discipline.

$$
* * *
$$

Cite this work:

KoUR, RANDHEER. 2020. Sympathy for the Traitor. Review of Sympathy for the Traitor, by Polizzotti, Mark. Translation Today, Vol. 14(1). 139142. DOI: $10.46623 / \mathrm{tt} / 2020.14 .1 . \mathrm{br} 4$ 